\title{
Study on Natural Convection in a Square Cavity with Wavy right vertical wall Filled with Viscous Fluid
}

\author{
Ramesh Chandra Mohapatra \\ Reader \& HOD, Mechanical Department, Government College of Engineering, Keonjhar, Orissa, India
}

\begin{abstract}
In the present study, natural convection problem has been solved in a cavity having three flat walls and the right vertical wall consisting of one undulation and three undulations. The two vertical and bottom walls are cold walls maintained at a fixed temperature whereas the top wall is heated with spatially varying temperature distribution. Air has been taken as the working fluid with $\mathrm{Pr}=0.71$. This problem is solved by SIMPLE algorithm with deferred QUICK scheme in curvilinear co-ordinates. A wide range of Rayleigh number $\left(10^{3}\right.$ to $\left.10^{6}\right)$ has been chosen for this study. For small Ra, the heat transfer was dominated by conduction across the fluid layers. With increase of Ra, the process began to be dominated by convection. In the presence of undulation the peak point of the heat rejection (negative local Nusselt number) in the right wall increases by $5.54 \%$ than left wall for $R a=10^{4}$. The three undulations case had maximum heat transfer to the uppermost undulation compared to that of the one undulation case.
\end{abstract}

Keywords: Natural convection, Wavy wall, Square cavity, Undulation, Nusselt number.

\section{Introduction}

Natural convection in fluid filled rectangular enclosures has received considerable attention in recent years because of its reliability, low cost, low noise and geometrical simplicity. The natural convection heat transfer from wavy surface is interest of several engineering applications such as cooling of electronic components and sealed electrical or electronic boxes, heating or cooling rooms, solar energy collector designs, heat exchanger designs etc. Taking all these under consideration, the characteristics of natural convection heat transfer are relatively important. Sarris et al. [1] studied the effect of heat transfer in a square enclosure by natural convection with periodic heating from above over the entire top wall and adiabatic bottom and sidewall boundary conditions. Their work was motivated by the need to understand the heat transfer characteristics in glass melting tanks, where a number of burners placed above the glass tank create periodic temperature profiles on the surface of the glass melt. Adjlout et al. [2] reported a numerical study of a hot wavy wall in an inclined differentially heated square cavity. Tests, for one and three undulations, were performed for different inclination angles, different amplitudes and Rayleigh numbers. The local heat transfer was also wavy and the mean Nusselt number decreased in comparison to the bare square cavity. Jang et al. [3] solved numerically the natural convection heat and mass transfer along a vertical wavy surface by using Prandtl's transposition theorem and investigated the effect of irregular surfaces on characteristics of natural convection heat and mass transfer. Das and Mahmud [4] analyzed the natural convection heat transfer inside both the bottom and the top wavy isothermal enclosures. They indicated that, only at low Grashof numbers, the heat transfer rate increased when the amplitude wave length ratio changed near zero values. Das et al. [5] numerically studied the effect of aspect ratio and surface waviness in an enclosure with top and bottom wavy walls. The results reported that natural convection heat transfer is changed considerably when surface waviness changes and also it depends on the aspect ratio of the domain. Dalal and Das [6] carried out a numerical solution to investigate the heat transfer from an inclined right wavy wall enclosure subjected to spatially varying temperature boundary condition. Varol and Oztop [7] analyzed the natural convection in a shallow wavy enclosure. Their results showed that heat transfer increased with the decreasing non-dimensional wave length and increased with the increasing aspect ratio and the Rayleigh number. Yao [8] investigated the natural convection along a vertical complex wavy surface. The numerical results showed that the enhanced heat transfer rate depended on the ratio of amplitude and wavelength of a surface. Sompong and Witayangkurn [9] studied numerically the natural convection in an enclosure filled with fluid-saturated porous media containing two wavy vertical walls. From the results it was observed that the increase of wave amplitude affects the flow intensity inside the cavity. Rahimi et al. [10] numerically studied Natural convection of mixture of nanoparticles and water near in a rectangular enclosure. They showed that the average Nusselt number increases by increasing nanoparticle volume fraction. Ramgadia and Saha [11] studied The effect of geometry on transition to unsteadiness. They reported by increasing the Reynolds number; the steady flow shows a decrease in thermal performance factor while an increase in thermal performance factor is noticed when the flow is unsteady. Cho et al. [12] and Mansour and Bakier [13] have been studied natural convection within a wavy enclosed cavity filled with nanofluid numerically. Both articles are the same. The obtained results shows that by tuning the wavy-surface geometry the heat transfer performance could 
be optimized. Morsli and Sabeur-Bendehina [14] investigated the natural convection and entropy generation inside a wavy wall square cavity. The total entropy generation is found to be increasing with increasing undulation number. Obayedullah et al. [15] have been studied the natural convection in a rectangular enclosure with sinusoidal temperature distribution at the bottom wall. Cho et al. [16] performed a numerical investigation on natural convection heat transfer performance and entropy generation within an enclosure containing nanofluids. An important result was the total energy generation can be minimized and the Nusselt number can be maximized via an appropriate tuning of the wavy surface geometry parameters.

\section{Problem Specification and Boundary Conditions}

The problem considered is a two-dimensional heat transfer in a square cavity with wavy right vertical wall filled with viscous fluid. The upper wall temperature is considered to be spatially varying with sinusoidal temperature distribution $T_{w}{ }^{*}\left(x^{*}\right)$. The other three walls are considered to be of constant temperature, $T_{c}{ }^{*}$. The temperature distribution on the top wall is as follows

$T_{w}^{*}\left(x^{*}\right)=T_{c}^{*}+\frac{\Delta T^{*}}{2}\left(1-\cos \left(\frac{2 \pi x^{*}}{L}\right)\right)$

where $T_{c}^{*}$ is the minimum value of the imposed temperature distribution, $\Delta T^{*}$ is the temperature difference between the maximum and the minimum temperatures of the upper wall, and $\mathrm{L}$ is the length of the enclosure. The above equation can be written in the dimensionless form as follows as shown in Fig.1:

$T_{w}(x)=\frac{1}{2}(1-\cos (2 \pi x))$

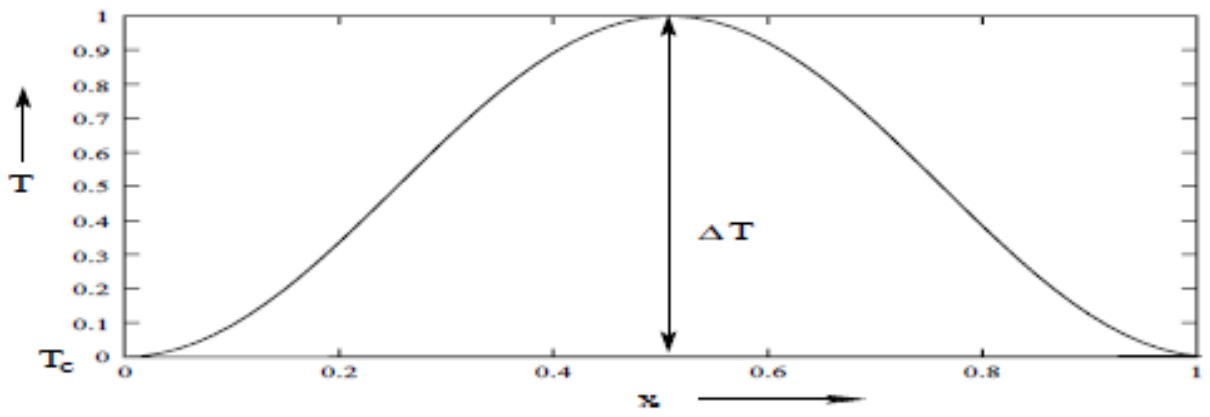

Figure 1: Sinusoidal temperature distribution at top wall

The right vertical wall is taken as sinusoidal varying. Two different cases with one and three undulation are studied. The amplitude for both the cases is taken as 0.05. The Rayleigh number is varied from $10^{3}$ to $10^{6}$. Prandtl number is fixed to be 0.71 . Figure 2 shows the geometrical features of the cavity. The velocity and temperature boundary conditions of the present problem are as follows:

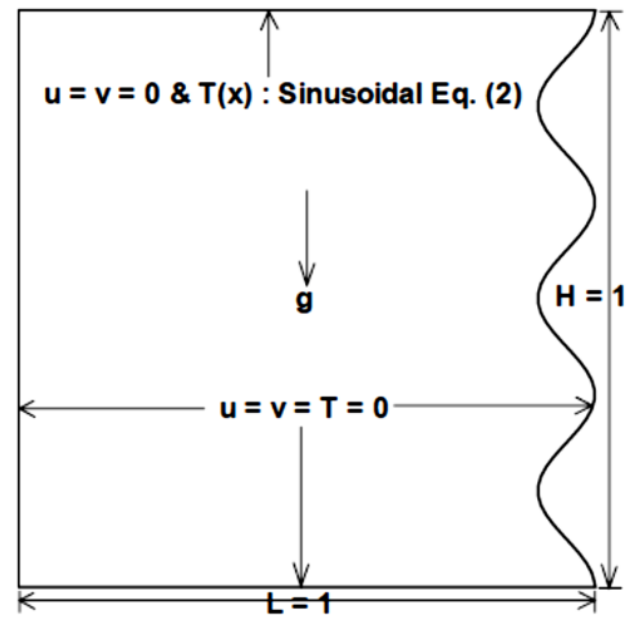

(b)

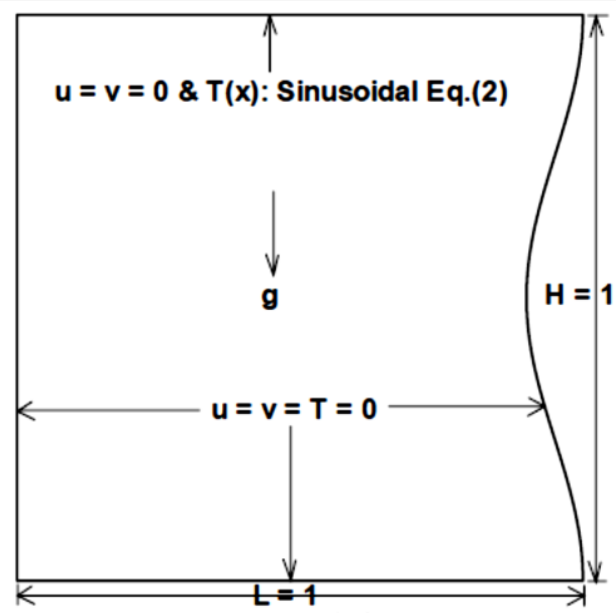

(a)

Figure 2: Flow configuration and boundary condition (a) One undulation (b) Three undulation 


$$
\begin{array}{lrl}
u & =v=T=0 & \text { for } x=0,1 \text { and } 0 \leq y \leq 1 \\
u & =v=T=0 & \text { fory }=0, \text { and } 0 \leq x \leq 1 \\
u & =v=0 \text { and } T=\frac{1}{2}(1-\cos (2 \pi x)) & \text { fory }=1 \text { and } 0 \leq x \leq 1
\end{array}
$$

The boundary conditions for computational form can be written as follows:

$u=v=T=0$

$u=v=T=0$

$u=v=0$ and $T=\frac{1}{2}(1-\cos (2 \pi x))$

$$
\begin{aligned}
& \text { for } \varepsilon=0,1 \text { and } 0 \leq \eta \leq 1 \\
& \text { for } \eta=0, \text { and } 0 \leq \varepsilon \leq 1
\end{aligned}
$$

$$
\text { for } \eta=1 \text { and } 0 \leq \varepsilon \leq 1
$$

\section{Results and Discussions}

A parametric study has been carried out to determine the influence of Rayleigh number on the flow field and effect of number of undulation on heat transfer. The results are for Rayleigh number of $10^{3}$ to $10^{6}$, Prandtl number of 0.71 , and the undulation amplitude of 0.05 . The discussion of the following results concern the temperature, streamline distributions, and the local Nusselt number on the walls. For higher Raleigh number convergence rate is very slow. Pseudo time steps $\Delta \Gamma$ for $\mathrm{Ra}=10^{3} ; 10^{4} ; 10^{5}$ and $10^{6}$ are $10^{-3} ; 10^{-3} ; 10^{-4}$ and $10^{-5}$ respectively to achieve stable solution.

\subsection{Cavity with one undulation}

Figure 3 (a)-(d) shows the streamline counter obtained for different Rayleigh numbers. A pair of counter rotating cells is formed in left and right halves of the enclosure. The fluid moves horizontally from the hotter middle of the upper wall toward its colder edge; then it descends along the cold side wall and finally it ascends near the mid-plane. The right cell is squeezed and small compared to left cell due to the present of undulation, but it has much less effect to the left cell. With increase of Rayleigh number, the intensity of the recirculation pattern increases and the centers of the cells move upward corners.

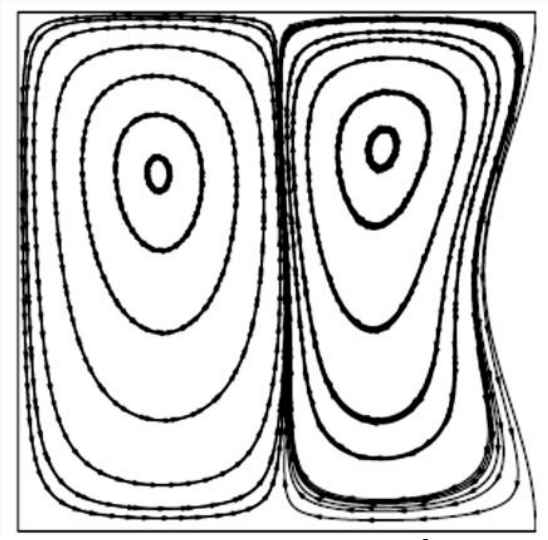

(a) $\mathrm{Ra}=10^{3}$

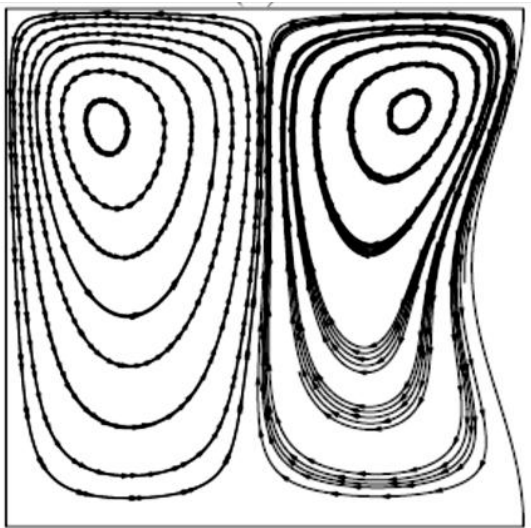

(c) $\mathrm{Ra}=10^{3}$

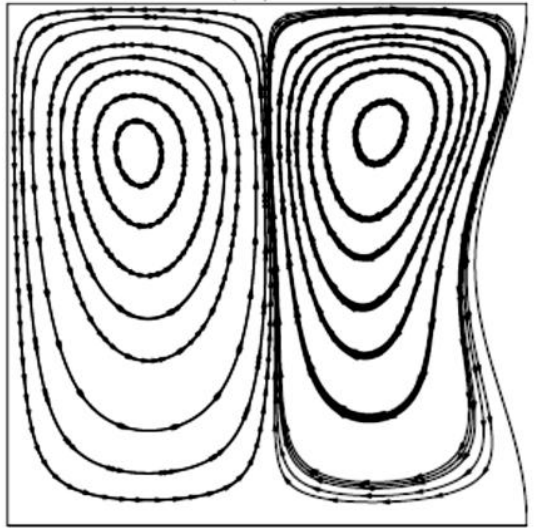

(b) $\mathrm{Ra}=10^{4}$

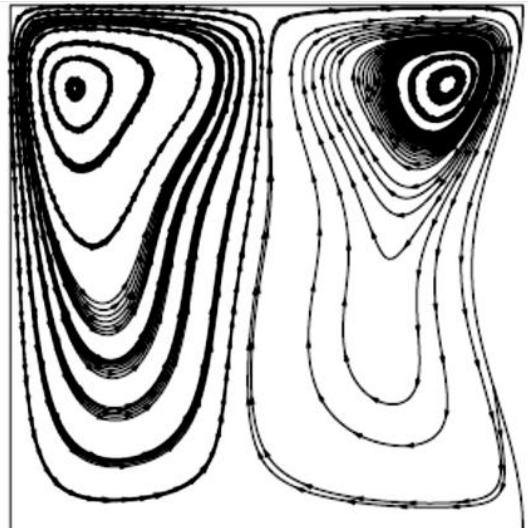

(d) $\mathrm{Ra}=10^{4}$

Figure 3: Streamline distribution for one undulation and different Rayleigh numbers 
Figure 4 (a)-(d) shows the isotherm counters obtained for different Rayleigh numbers. For lower value of Rayleigh number $\left(10^{3}\right.$ and $\left.10^{4}\right)$, the temperature fronts penetrate from the upper wall to bottom wall, as conduction is the main heat transfer mechanism in this case. The isotherms for higher Rayleigh number $\left(10^{5}\right.$ and $10^{6}$ ) concentrate near the upper wall, because the advection mode of the heat transfer dominates over conduction.

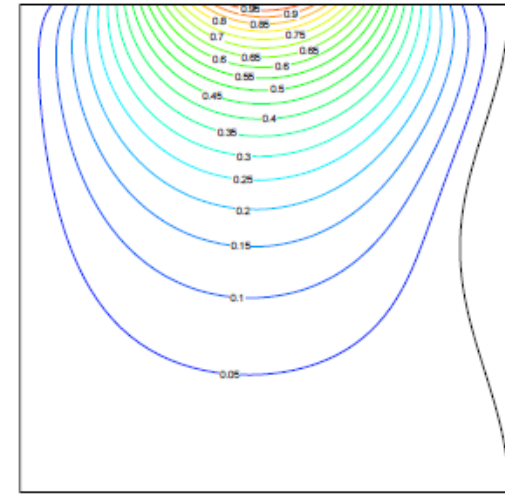

(a) $\mathrm{Ra}=10^{3}$

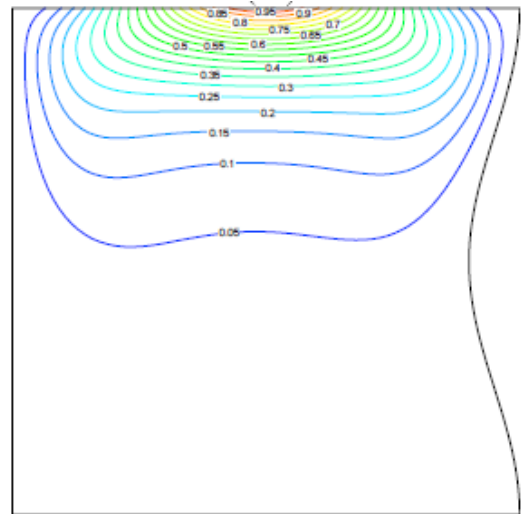

(c) $\mathrm{Ra}=10^{3}$

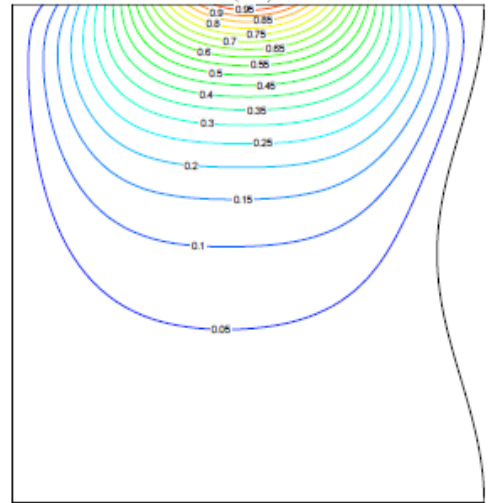

(b) $\mathrm{Ra}=10^{4}$

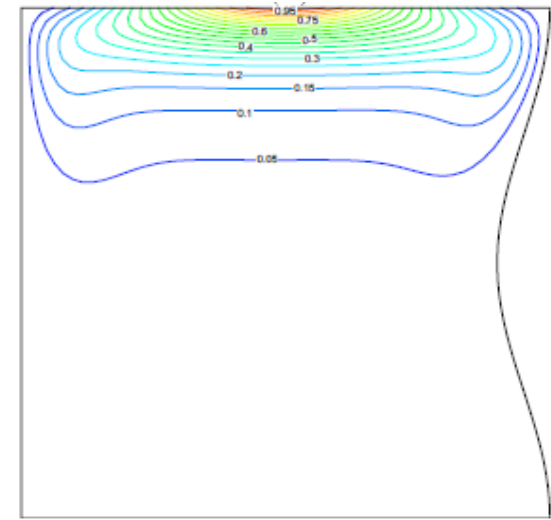

(d) $\mathrm{Ra}=10^{4}$

Figure 4: Temperature distribution for one undulation and different Rayleigh numbers

The effect of undulation on local Nusselt number is shown in Fig.5 (a)-(d). Figure 5(a) shows the variation of local Nusselt number along the top wall for the Rayleigh numbers studied. The higher the Rayleigh number, the larger the amount of heat added to the fluid in the central region of the enclosure. In the middle region of the top wall the cold fluid that is brought there by the recirculation patterns from the lower part of the enclosure is heated up and as a result the local Nusselt number become positive there. The heated fluid from the middle of the upper wall reaches the enclosure corners, losing heat to the upper wall, and thus the local Nusselt number becomes negative there. For the higher Rayleigh numbers, the recirculation centers become very close to the top wall while the recirculation intensity increases, producing two peaks in the Nusselt number near the top corners of the enclosure.

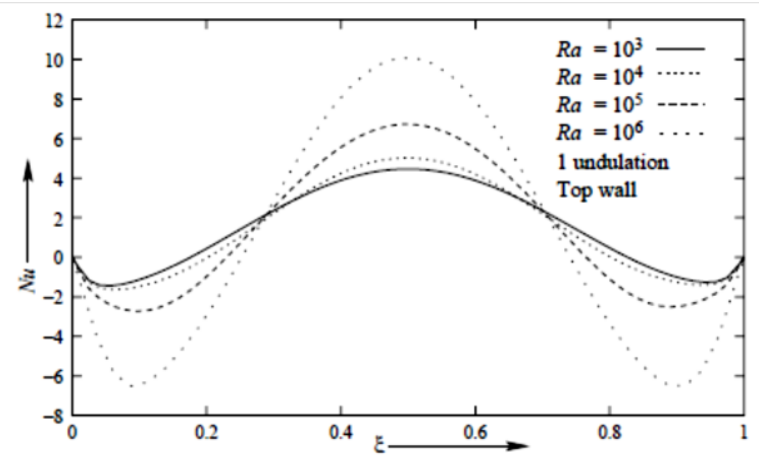

Figure: 5(a) Local Nusselt number distribution for one undulation at top wall 
Figure 5(b)-(c) shows the variation of local Nusselt number along the right and left wall respectively. The higher the Rayleigh number, the larger the amount of heat rejected from the fluid to right wall near the top corners of the enclosure. As the recirculation intensity increases close to the upper wall, the peak in the Nusselt number is produced near the top corners for both cases. Figure 5(d) shows the comparison of variation of Nusselt number between right wall and left wall in presence of one undulation for Ra $=10^{4}$. In the presence of undulation the peak point of the heat rejection (negative local Nusselt number) in the right wall increases by $5.54 \%$ than left wall for $\mathrm{Ra}=10^{4}$.

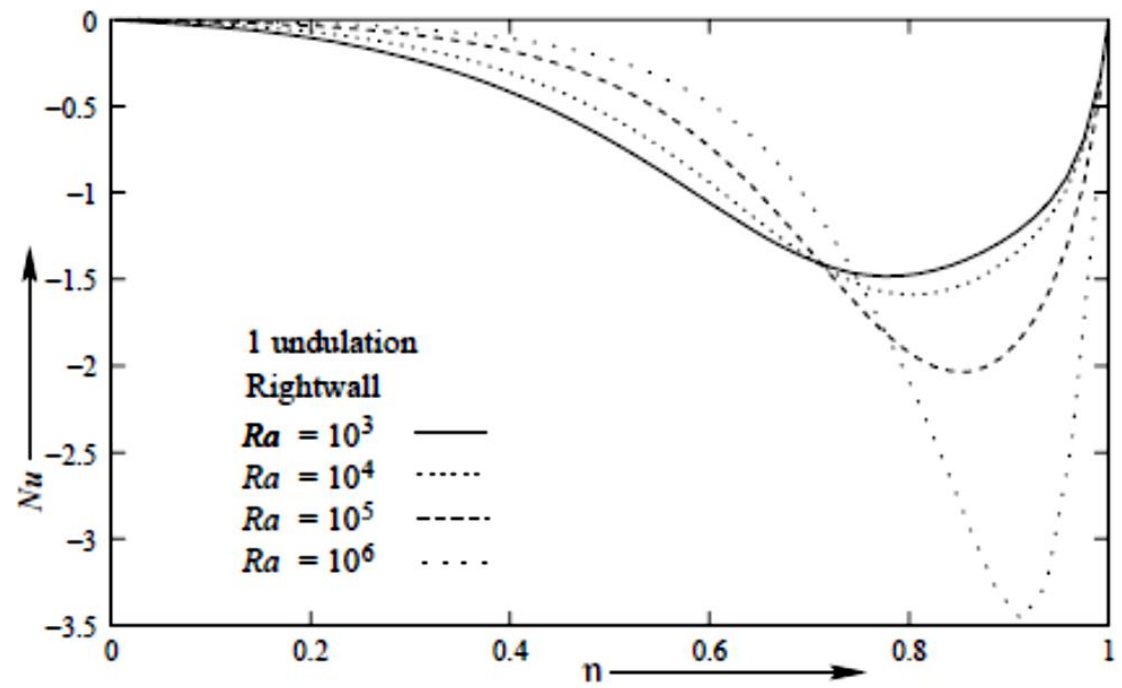

Figure: 5(b) Local Nusselt number distribution for one undulation at right wall

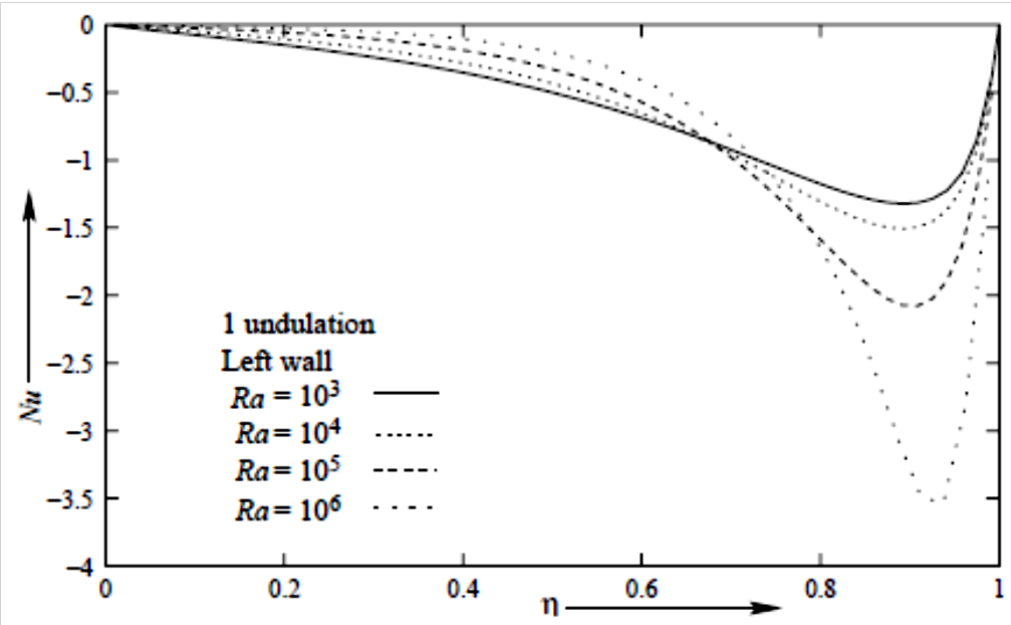

Figure: 5(c) Local Nusselt number distribution for one undulation at left wall

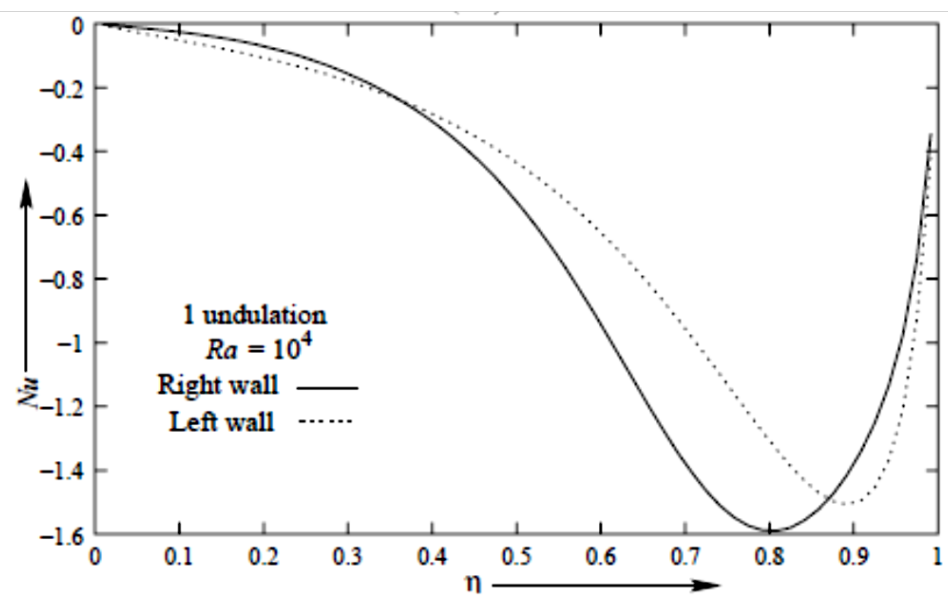

Figure: 5(d) Local Nusselt number distribution for one undulation at $\mathrm{Ra}=10^{4}$ 


\subsection{Cavity with three undulations}

The streamline distribution and isotherm pattern inside the cavity with three undulations are presented in Fig. 6(a)-(h) for different Rayleigh number. It is clear that the undulated wall has an influence on the streamline pattern. The main flow is observed to be in the counter clockwise direction because the sinusoidal varying temperature is on the right side of the gravity vector. The circulation is setting in because the hot fluid is rising up displacing cold fluid and thus a counter clockwise flow is occurring. The isotherms concentrate near the heated wall and heat transfer is high. However half of the domain is very cold signifying the heat is unable to penetrate in this region.

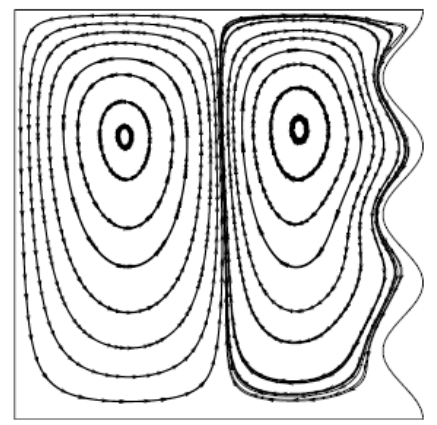

(a) $\mathrm{Ra}=10^{3}$

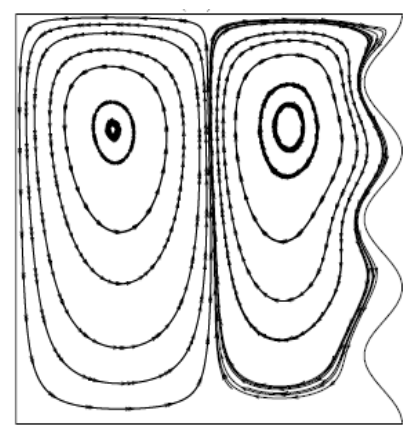

(c) $\mathrm{Ra}=10^{4}$

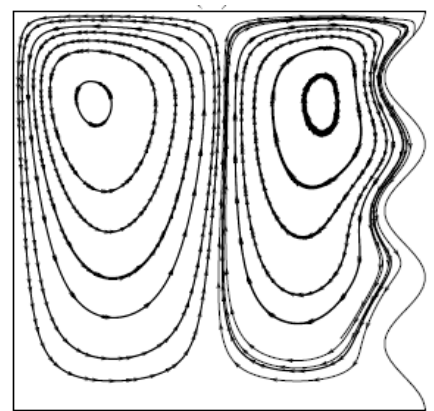

(e) $\mathrm{Ra}=10^{5}$

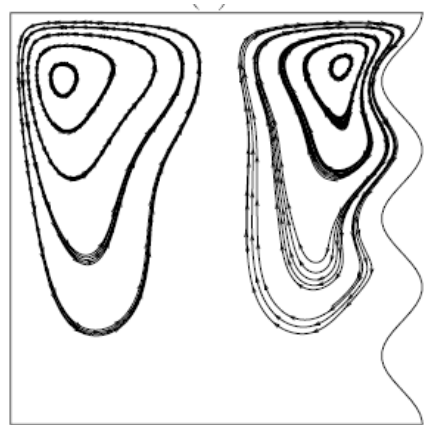

(g) $\mathrm{Ra}=10^{6}$

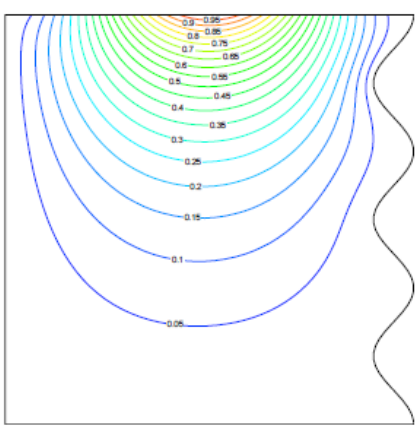

(b)

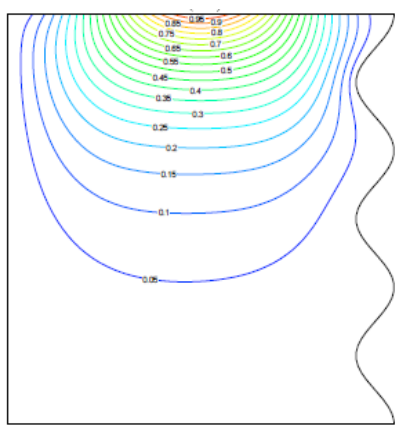

(d)

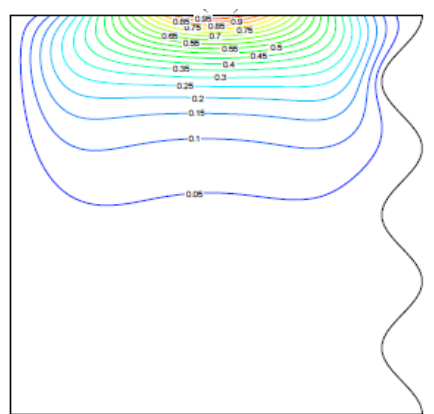

(f)

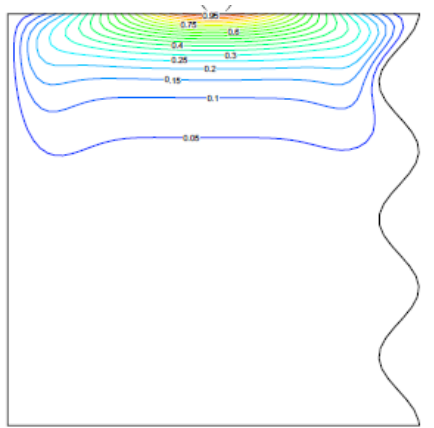

(h)

Figure 6: Streamline and Temperature distribution for three undulation and different Rayleigh numbers 
Figure 7(a) shows the variation of local Nusselt number along the top wall for the Rayleigh numbers studied. From this figure it was found that the higher the Rayleigh number, the larger the amount of heat added to the fluid in the central region of the enclosure. In the middle region of the top wall the cold fluid that is brought there by the recirculation patterns from the lower part of the enclosure is heated up and as a result the local Nusselt number become positive there.

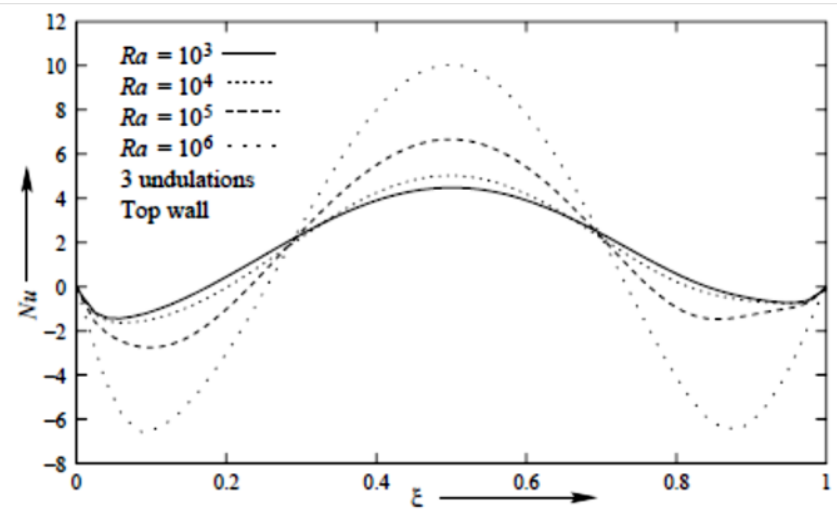

Figure: 7(a) Local Nusselt number distribution for three undulation at top wall

Fig.7(b) shows the local Nusselt number distribution on the right wall. It reveals that the thermal boundary layer thickness on the side of the undulated wall increases and decreases just before a crest or just after a trough. The highest peak of the local Nusselt number occurs near the top corner,i.e for the last undulation in the positive y-direction where as it is decreasing near the bottom potion of the wavy wall. For three undulations, there are three maxima. From the fig. 7(b), it is concluded that at the uppermost undulation the largest $\mathrm{Ra}$ has the highest $\mathrm{Nu}$ value where as for bottom undulation, it has the lowest $\mathrm{Nu}$ value. Here, heat rejection (-ve $\mathrm{Nu}$ ) increases with increase of $\mathrm{Ra}$.

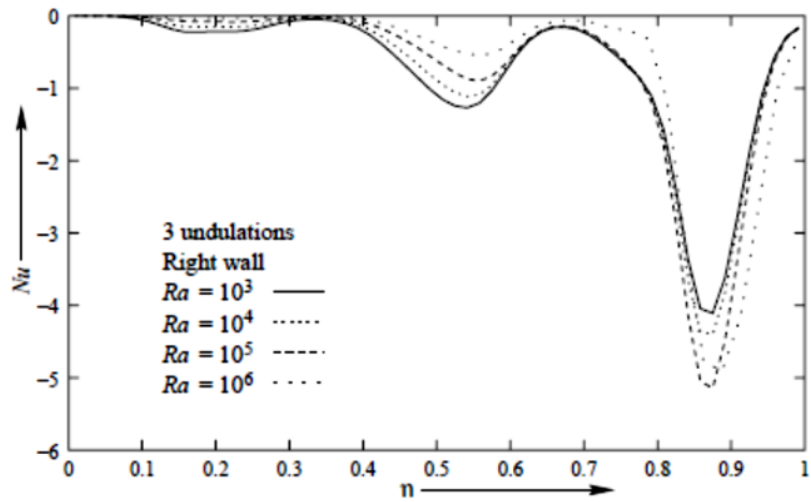

Figure: 7(b) Local Nusselt number distribution for three undulation at right wall

Fig. 7 (c)-(d) shows a comparison between one undulation and three undulation for top wall as well as bottom wall. On comparison, it is found that the increase in heat rejection (-ve $\mathrm{Nu}$ ) is not appreciable and it is to be noted that heat rejection (-ve $\mathrm{Nu}$ ) decreases with increase in Ra for this region. This is happening because the gradient of temperature decreases near the bottom of the enclosure with increase of Rayleigh number.

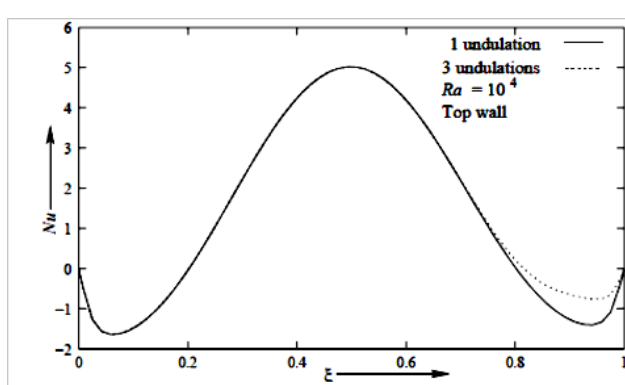

(c)

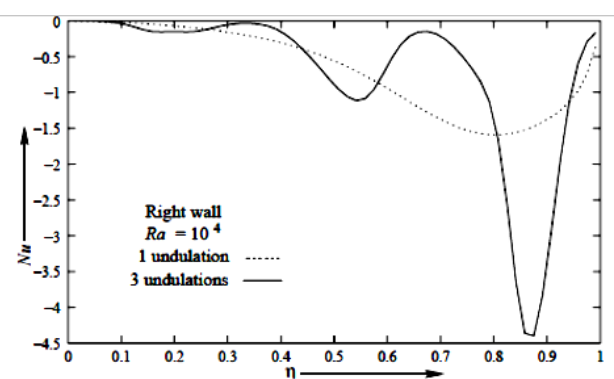

(d)

Figure: 7 (c)-(d) Comparison of Local Nusselt number between one undulation and three undulation 


\section{Conclusion}

Effect of heat transfer on the undulated cold wall by natural convection in a complicated cavity With sinusoidal temperature boundary condition on the upper wall and constant cold temperature boundary condition on other three walls were studied. Results were presented for $\mathrm{Ra}=10^{3}, 10^{4}, 10^{5}, 10^{6}$ and $\operatorname{Pr}=0.71$. For small Ra, the heat transfer was dominated by conduction across the fluid layers. With increase of Ra, the process began to be dominated by convection. For three undulations case, there was a marked increase in heat transfer to the uppermost undulation, and no appreciable improvement of heat transfer was noticed at bottom two undulations. In other words, the bottom two undulations were not effective whereas the uppermost undulation was most effective as far as heat transfer was concerned. The three undulations case had maximum heat transfer to the uppermost undulation compared to that of the one undulation case.

\section{Nomenclature: \\ $\operatorname{Pr}$ \\ $\mathrm{Ra}$ \\ $\mathrm{Nu}$

Abbreviations
SIMPLE
QUICK

\author{
Prandtl Number \\ Rayleigh Number \\ Local Nusselt Number
}

Semi-Implicit Method for Pressure-Linked Equation

Quadratic Upstream Interpolation for Convective Kinematics

\section{Acknowledgements}

Dr. Ramesh Chandra Mohapatra was born in Orissa, India in 1969. He graduated from Department of Mechanical Engineering of UCE, Burla, now VSSUT, Burla, Orissa, India. He received the degree of M.Tech in Thermal Engineering from Department of Mechanical Engineering of Indian Institute of Technology (IIT), Kharagpur, Orissa, India in 2011 and $\mathrm{PhD}$ in Mechanical Engineering from Utkal university,Vanivihar, Bhubaneswar, Orissa, India. He is presently working as Reader \& HOD of Mechanical Engineering Department in Government College of Engineering, Keonjhar, Orissa, India

\section{References}

[1]. Sarris, I. E., Lekakis, I., and Vlachos, N. S., 2002, "Natural Convection in a 2D Enclosure with Sinusoidal Upper Wall Temperature," Numerical Heat Transfer, Vol. 42, Part A, pp. 513-530.

[2]. Adjlout, L., Imine, O., Azzi, A, and Belkadi, M., 2002, "Laminar Natural Convection in an Inclined Cavity with a Wavy Wall," International Journal of Heat \& Mass Transfer, Vol. 45, pp. 2141-2152.

[3]. Jang, J. H., Yan, W. M. and Liu, H. C., 2003, "Natural convection heat and mass transfer along a vertical wavy surface", International Journal of Heat and Mass Transfer, Vol. 46, pp.1075-1083.

[4]. Das, P. K. and Mahmud, S., 2003, "Numerical investigation of natural convection inside a wavy enclosure", International Journal of Thermal Science, Vol.42, pp. 397-406.

[5]. Das, P. K., Mahmud, S., Tasnim, S. H., \& Islam, A. S., 2003, "Effect of surface waviness and aspect ratio on heat transfer inside a wavy enclosure", International Journal of Numerical Methods for Heat \& Fluid Flow, Vol.13(8), pp.1097-1122.

[6]. Dalal, A. and Das, M.K., 2005, "Laminar natural convection in an inclined complicated cavity with spatially variable wall temperate", International Journal of Heat and Mass Transfer, Vol.48, pp.3833-3854.

[7]. Varol, Y. and Oztop, H. F., 2006, "Free convection in a shallow wavy enclosure", International Communications in Heat and Mass Transfer, Vol.33, pp.764-771.

[8]. Yao, L. S., 2009, "Natural convection along a vertical complex wavy surface", International Journal of Heat and Mass Transfer, Vol.49, pp.281-286.

[9]. Sompong, P., \& Witayangkurn, S., (2012), "Simulation of natural convection in a complicated enclosure with two wavy vertical walls", Applied Mathematical Sciences, Vol.6 (57-60), pp.2833-2842.

[10]. Rahimi, M., Ranjbar, A. A., Hosseini, M. J., \& Abdollahzadeh, M., 2012, "Natural convection of nanoparticle-water mixture near its density inversion in a rectangular enclosure", International Communications in Heat and Mass Transfer, Vol.39 (1), pp.131-137.

[11]. Ramgadia, A. G., \& Saha, A. K., 2012, "Fully developed flow and heat transfer characteristics in a wavy passage: Effect of amplitude of waviness and Reynolds number", International Journal of Heat and Mass Transfer, Vol.55 (9), pp.2494-2509.

[12]. Cho, C. C., Chen, C. L., \& Chen, C. O. K., 2012, "Natural convection heat transfer performance in complex-wavy-wall enclosed cavity filled with nano-fluid", International Journal of Thermal Sciences, Vol.60, pp.255-263.

[13]. Mansour, M. A., \& Bakier, M. A. Y., 2013, "Free convection heat transfer in complex-wavy-wall enclosed cavity filled with nanofluid" International Communications in Heat and Mass Transfer, Vol.44, pp.108-115.

[14]. Morsli, S., \& Sabeur-Bendehina, A., 2013, "Entropy generation and natural convection in square cavities with wavy walls", Journal of Applied Mechanics and Technical Physics,Vol.54 (6), pp.913-920.

[15]. Obayedullah, M., Chowdhury, M. M. K., \& Rahman, M. M., 2013, "Natural convection in a rectangular cavity having internal energy sources and electrically conducting fluid with sinusoidal temperature at the bottom wall", International Journal of Mechanical and Materials Engineering,Vol.8 (1), pp.73-78.

[16]. Cho, C. C., Chen, C. L., \& Chen, C. O. K., 2012, "Natural convection heat transfer performance in complex-wavy-wall enclosed cavity filled with nanofluid”, International Journal of Thermal Sciences, Vol.60, pp.255-263. 